\title{
Dentition Status and Treatment Needs of 5 and 12 Year Old School Children in Urban and Rural Areas of Guntur, India
}

\author{
V Narayana Rao', Suresh S', Zaheer Ahmed ${ }^{3}$, Pratap KVNR
}

\begin{abstract}
Objective: To describe the caries prevalence and treatment needs of 5 and 12 year old school children in urban and rural areas of Guntur.

Materials and Methods: A multi stage random sampling was used to select the sample; survey was conducted among 800 children of 5 and 12 year old in government and private schools from rural and urban areas of Guntur.

Results: The caries prevalence of 5 year olds was $33.25 \%$ (urban $32.5 \%$ and; rural $34 \%$ ) and mean dmft was $0.83 \pm 1.5$ (urban 0.71 and rural 0.95 ). The caries prevalence of 12 year olds was $25.75 \%$ (urban $31.5 \%$ and rural 20\%) and mean dmft was $0.41 \pm 0.89$ (urban 0.54 and rural 0.28 ).

Conclusion: caries prevalence was greater in deciduous teeth of 5 year old children than that in permanent dentition of 12 year old children. Among 12 year olds caries prevalence was greater in urban subjects than rural subjects. There is a huge unmet treatment need for dental caries. There is a definite need to bring awareness and motivation in these children to undergo preventive and curative treatments in order to improve their oral health.
\end{abstract}

Keywords: Prevalence, Dental Caries, Urban and Rural Children.

${ }^{1}$ Assistant Professor

Department of Public Health Dentistry Kamineni Institute of Dental Sciences Narketpally, Nalgond District,

Andhra Pradesh, India

${ }^{2}$ Assistant Professor

Department of Public Health Dentistry

Kamineni Institute of Dental Sciences

Narketpally, Nalgond District,

Andhra Pradesh, India

${ }^{3}$ Assistant Professor

Department of Public Health Dentistry Navodaya Dental College and Hospital

Raichur, Karnataka, India

${ }^{4}$ Head of the Department

Department of Public Health Dentistry

SIBAR Institute of Dental Sciences, Guntur,

Andhra Pradesh, India

\section{Contact Autbor}

Dr. V Narayana Rao narayanarao1982@gmail.com

J Oral Health Comm Dent 2012;6(3)126-130

\section{INTRODUCTION}

Dental caries constitutes the major oral health problem in most regions of the world. There are practically no geographical areas in the world whose inhabitants do not exhibit some evidence of dental caries. It is the most prevalent chronic disease effecting persons of both sexes in all races, all socioeconomic strata and every age group especially children(1). Dental caries because of its ubiquitous nature remains one of the most prevalent afflictions of mankind. This can aptly be termed as a scourge of modern civilization and no nation or continent has escaped the ill effects of this deadly malady(2). Once it occurs, its manifestations persist throughout life even though the lesion is treated.

Prevalence of dental caries has declined in the past 20 years in many developed coun- tries, while its prevalence and severity is increasing in many developing countries(3). Epidemiological studies of dental caries and periodontal diseases in different parts of India have reported high prevalence of oral diseases(4). Prevalence of dental caries was about $50 \%$ in 5 year old children and about $84.1 \%$ in older age population as reported by National oral health survey and fluoride mapping 2002-2003(5).

Guntur is fifth largest city in Andhra Pradesh. The city has an estimated population of 818,330 (514,707 as per 2001 census) (6) and it is typical of the wider deltas along the southeast coast of India (known as the Coromandel Coast). Prevention of dental caries before its occurrence by implementing preventive programs helps in reduction of prevalence of dental caries in children and improvement of oral as well 
as general health. In order to plan a preventive programme data regarding the caries prevalence is required. There were very few studies that have been conducted in Andhra Pradesh and there was no data regarding dental caries in Guntur. Hence the present study was carried out to assess the prevalence of dental caries and treatment needs in 5 and 12 year old school going urban and rural children of Guntur.

\section{MATERIALS AND METHODS}

Information regarding the number of government primary and upper primary schools in Guntur was procured from the office of the Mandal Education Officer (MEO) and private schools list was procured from president of Andhra Pradesh Tutorials and Convents Association, Guntur division. There are about 114 government schools and 58 private schools in Guntur urban and rural areas.
A pilot study was conducted using the same population group of 30 subjects and were examined using study proforma, these same subjects were reexamined on later date and $90 \%$ of reproducibility was found on all the subjects and intraexaminar calibration was achieved. Based on the results of pilot study, the sample size was determined to be 800 . The required power of the study was set at $80 \%$.

In order to collect the representative sample, multi stage random sampling procedure was executed. At first stage the schools were divided based on the regions they were located i.e., North, South, East and West. A total of 16 schools were selected based on lottery system (simple Random Sampling) from all these four regions, from each selected school 25 children each from 5 and 12 year old groups were randomly selected. Figure 1 depicts the sampling technique.

Subsequently, 400 (200 urban and $200 \mathrm{ru}-$ ral) 5 year old children and 400 (200 urban and 200rural) 12 year old children were selected as the final sample. Ethical clearance to conduct the study was obtained from Institutional review board of SIBAR institute of dental sciences Guntur and official permission was obtained from District Education Officer (DEO) and the concerned school authorities, written consent was obtained from the parents of randomly selected children.

The examination for dental caries was made according to the dentition status and treatment needs as described by WHO 1997 (7) using community periodontal index probe and plane mouth mirror (American Den-

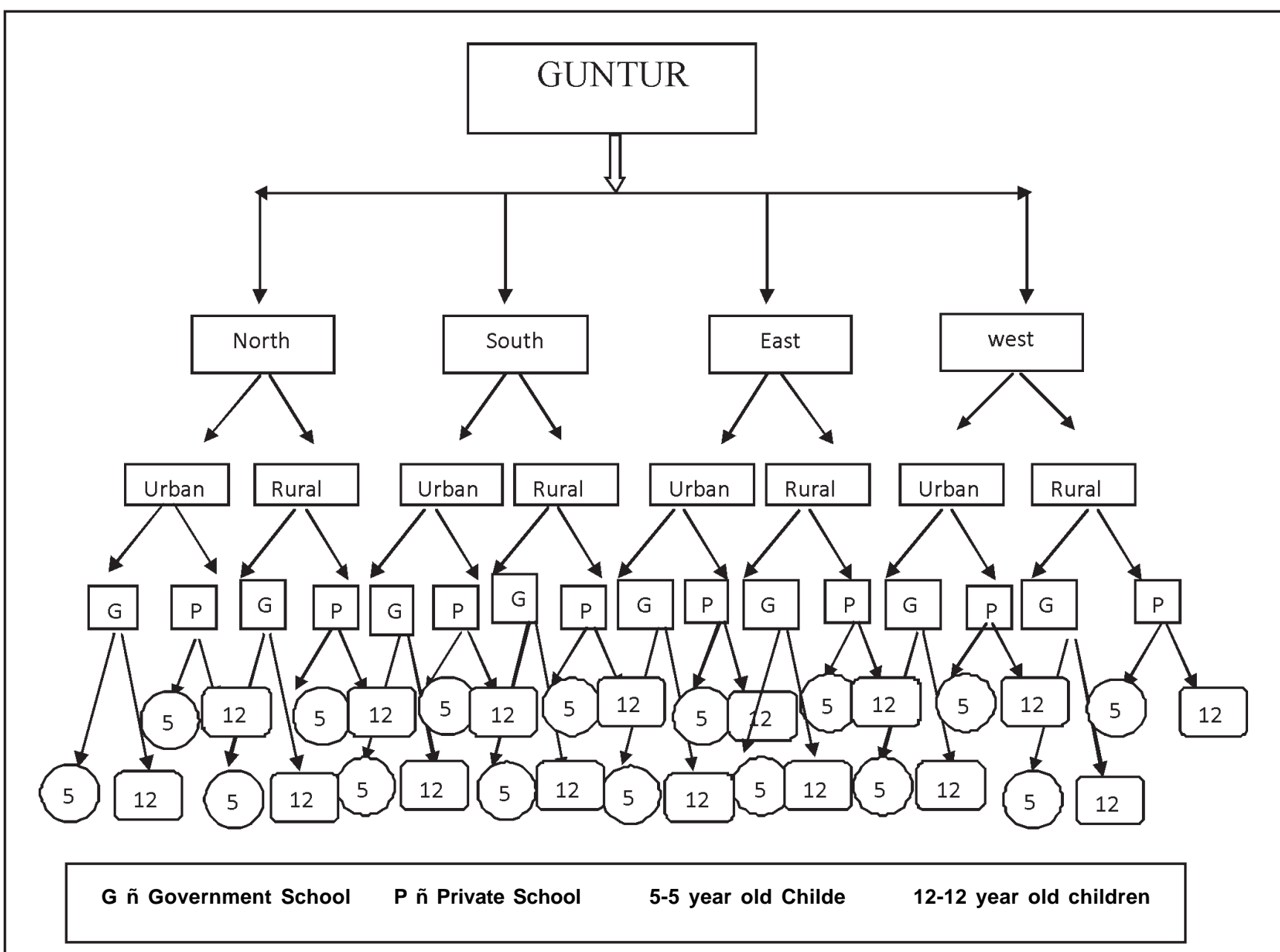

Figure 1: Sampling method employed in selecting the required sample 
tal Association type III examination) under natural day light in school premises.

\section{STATISTICAL ANALYSIS}

The data was transferred from pre coded survey proforma to a computer. Descriptive statistics that include mean, standard deviation and percentages were calculated for each of the categories. t-test was used to determine whether significant differences were present in mean $\mathrm{dmft} / \mathrm{DMFT}$ between groups. Categorical data were analyzed by Chi-square test for differences between groups. Significance for all statistical tests was predetermined at a probabil- ity value of less than 0.05. Data was analyzed using statistical package SPSS 15.

\section{RESULTS}

Table 1 shows the distribution of children according to age, location and gender, total sample representing both the age groups 5 and 12 year olds was 800 .

Caries prevalence was 36.6\%, 34.6\%, 28.2 $\%$ and $33.3 \%$ among urban boys, rural boys, urban girls and rural girls respectively. Although there was a difference in prevalence of dental caries among boys and girls, it was not statistically significant. In boys

\section{Table 1: Distribution of children according to age, location and gender}

\begin{tabular}{|c|c|c|c|c|}
\hline \multirow[t]{2}{*}{ Age } & \multirow[t]{2}{*}{ Location } & \multicolumn{2}{|c|}{ Gender } & \multirow[t]{2}{*}{ Total } \\
\hline & & Boys & Girls & \\
\hline \multirow[t]{2}{*}{5 yrs } & Urban & 101 & 99 & 200 \\
\hline & Rural & 101 & 99 & 200 \\
\hline \multirow[t]{2}{*}{$12 y r s$} & Urban & 100 & 100 & 200 \\
\hline & Rural & 98 & 102 & 200 \\
\hline Total & & 400 & 400 & 800 \\
\hline
\end{tabular}

the mean $\mathrm{dmft}$ was $0.77 \pm 1.34$ and $1.01 \pm 1.83$ in urban and rural area respectively. In girls the mean $\mathrm{dmft}$ was $0.65 \pm 1.38$ and $0.88 \pm 1.68$ in urban and rural area respectively. Although there was difference observed in caries experience this difference was not statistically significant. (Table 2)

Table 3 shows the dental caries prevalence in 12 year old school children according to sex and location. Caries prevalence was $36 \%$, $22.4 \%, 27 \%$ and $17.6 \%$ among urban boys, rural boys, urban girls and rural girls respectively. Although there was a difference in prevalence of dental caries among boys and girls, it was not statistically significant. Caries experience (mean DMFT) in 12 year old children according to sex and location. In boys the mean DMFT observed was $0.71 \pm 1.24$ and $0.30 \pm 0.79$ in urban and rural areas respectively. In girls the mean DMFT was $0.38 \pm 0.73$ and $0.25 \pm 0.59$ in urban and rural areas respec-

Table 2. Prevalence of dental caries and mean dmft in 5 year old school children in urban and rural areas

\begin{tabular}{|c|c|c|c|c|c|c|c|}
\hline \multirow[t]{2}{*}{ Location } & \multirow{2}{*}{$\begin{array}{c}\text { No of } \\
\text { subjects }\end{array}$} & \multicolumn{2}{|c|}{ Boys } & \multicolumn{2}{|c|}{ Girls } & \multicolumn{2}{|c|}{ Total } \\
\hline & & Affected (\%)* & Mean dmft ${ }^{* *}$ & Affected(\%)* & Mean $d m f t^{\star *}$ & Affected(\%) & Mean dmft \\
\hline Urban & 200 & $37(36.6 \%)$ & $0.77 \pm 1.34$ & $28(28.2 \%)$ & $0.65 \pm 1.38$ & $65(32.50 \%)$ & $0.71 \pm 1.36$ \\
\hline Rural & 200 & $35(34.6 \%)$ & $1.01 \pm 1.84$ & $33(33.3 \%)$ & $0.88 \pm 1.68$ & $68(34 \%)$ & $0.95 \pm 1.76$ \\
\hline
\end{tabular}

Table 3: Prevalence of dental caries and mean DMFT in 12 year old school children in urban and rural areas

\begin{tabular}{|c|c|c|c|c|c|c|c|}
\hline \multirow[t]{2}{*}{ Location } & \multirow{2}{*}{$\begin{array}{c}\text { No of } \\
\text { subjects }\end{array}$} & \multicolumn{2}{|c|}{ Boys } & \multicolumn{2}{|c|}{ Girls } & \multicolumn{2}{|c|}{ Total } \\
\hline & & Affected (\%)* & Mean DMFT ** & Affected(\%)* & Mean DMFT ${ }^{\star \star}$ & Affected(\%) & Mean DMFT \\
\hline Urban & 200 & $36(36 \%)$ & $0.71 \pm 1.24$ & $27(27 \%)$ & $0.38 \pm 0.73$ & $63(31.50 \%)$ & $0.54 \pm 1.03$ \\
\hline Rural & 200 & $22(22.4 \%)$ & $0.30 \pm 0.79$ & $18(17.6 \%)$ & $0.25 \pm 0.59$ & $40(20 \%)$ & $0.28 \pm 0.69$ \\
\hline
\end{tabular}

\section{Table4: Prevalence of dental caries in 5 and 12 year old urban and rural children according to diet}

\begin{tabular}{|c|c|c|c|c|c|c|c|}
\hline \multirow[t]{2}{*}{ Location } & \multirow{2}{*}{$\begin{array}{c}\text { Age } \\
\text { group }\end{array}$} & \multicolumn{3}{|c|}{ Vegetarian } & \multicolumn{3}{|c|}{ Mixed diet } \\
\hline & & No. of subjects & Caries free (\%) & Affected(\%) & No. of subjects & Caries free (\%) & Affected(\%) \\
\hline \multirow[t]{2}{*}{ Urban } & $5 y r{ }^{*}$ & 53 & $31(58 \%)$ & $22(42 \%)$ & 147 & $104(71 \%)$ & $43(29 \%)$ \\
\hline & $12 y r s$ ** & 44 & $30(68 \%)$ & $14(32 \%)$ & 156 & $107(69 \%)$ & $49(31 \%)$ \\
\hline \multirow[t]{2}{*}{ Rural } & $5 y r s *$ & 20 & $14(70 \%)$ & $6(30 \%)$ & 180 & $148(82 \%)$ & $32(18 \%)$ \\
\hline & $12 \mathrm{yrs}$ ** & 22 & $16(70 \%)$ & $6(30 \%)$ & 178 & $144(81 \%)$ & $34(19 \%)$ \\
\hline
\end{tabular}


tively. Although there was difference observed in caries experienced this difference was not statistically significant.

In both urban and rural areas the prevalence of dental caries was more in vegetarians than people on mixed diet and this difference was statistically significant. (Table 4)

Table 5 shows the distribution of treatment needs in 5 year olds in urban and rural areas. Among urban school children $20 \%$ required one surface filling, $1 \%$ required pulp care, and $40 \%$ required treatments. Where as in rural area $7.5 \%$ required preventive care, $24.5 \%$ required two or more surface filling, and total of $55.5 \%$ required treatments is rural area. This difference observed was significant statistically.

Among urban school children $24 \%$ required one surface filling, $2 \%$ required pulp care, and a total of $58 \%$ required treatments in urban area. In rural area 10\% required fissure sealants, $1 \%$ required pulp care and a total of $41 \%$ required treatments is rural area. This difference observed was significant statistically.(Table 6)

\section{Table 5: Treatment needs of 5 year old children according to location}

\begin{tabular}{|lrrr|}
\hline Treatment needs & Urban (\%) & Rural (\%) & Total (\%) \\
\hline Preventive care & $10(5.00)$ & $15(7.50)$ & $25(6.25)$ \\
One surface filling & $40(20.00)$ & $23(11.50)$ & $63(15.75)$ \\
Two or more surface filling & $18(9.00)$ & $49(24.50)$ & $67(16.75)$ \\
Pulp care & $2(1.00)$ & $0(0.00)$ & $2(0.50)$ \\
Extraction & $10(5.00)$ & $24(12.00)$ & $34(8.50)$ \\
Total & $80(40.00)$ & $111(55.50)$ & $191(47.75)$ \\
$\chi^{2}=23.19, \mathrm{P}=0.000$, Highly Significant & & & \\
\hline
\end{tabular}

\section{Table 6: Treatment needs of 12 year old children according to location}

\section{Treatment needs}

Preventive care

Fissure sealant

One surface filling

Two or more surface filling

Pulp care

Extraction

Total

$\chi^{2}=8.76, P=0.033$, Significant

\section{DISCUSSION}

It has always been a challenge for epidemiological studies to obtain the appropriate representation of target population, school going children of concerned regions has been considered as good sample source for conducting such work in children(8). The present study was conducted among 5 and 12 year old school going children in urban and rural areas of Guntur.

In the present study it has been observed that the overall prevalence of dental caries was $29.5 \%$, where as the prevalence of dental caries among 5 year old children were $33.25 \%$ and that of 12 year old children was $25.75 \%$. The prevalence of dental caries was lower than the national average prevalence observed in national oral health survey and fluoride mapping2002-2003 India in 5 and 12 year old children (5) was $50 \%$ in 5 years (primary teeth) and 52.5\% in 12 years.

Among 5 year old caries prevalence and mean $\mathrm{dmft}$ was slightly more in rural area compared to urban area. Similar results were observed in the study conducted by Wong et al (9) Yee $\mathrm{R}$ et al(10). The difference observed might be due change in diet of chil-

\section{the present study it has been observed that the prevalence of caries was more in vegetarians than mixed diet group in both urban and rural areas of 5 year and 12 years. Similar results were observed by study done by Satish Chandra et al, (13) Sherfudhin et al (14).}

In the present study it has been observed that the dental caries prevalence was higher in boys than girls in 5 year old children as well as in 12 year old children in both urban and rural areas. Similar results were obtained by studies conducted by Das et al, (15) Maheshkumar et al,(16) Wong et al,(9) Sebastein et al,(4) Gaikward et al,(17) SK. Gangwar et al,(18) Yee et al (10). This is perhaps due to the fact that younger boys are fed with more sweets by their parents and boys taking more snacks between meals for their longer outdoor stay.

In both the age groups only $\mathrm{d} / \mathrm{D}$ components accounts the whole of $\mathrm{dmft} / \mathrm{DMFT}$. None of the examined children had missing or filled $(\mathrm{M} / \mathrm{m}, \mathrm{f} / \mathrm{F})$ component. This reflects the lack of attention towards the oral health in both urban and rural areas.

\section{CONCLUSION}

Even though prevalence of caries was low when compared to other studies there was a difference in caries prevalence in urban and rural school children. Almost all the children examined had never underwent any dental treatment. All were suffering from untreated decay. Further detailed studies are needed to study the difference in prevalence of dental caries between rural and urban areas across various socio-economic groups and to understand the barriers that are preventing school children from utilizing dental health care services. 


\section{REFERENCES}

1. Shafer, Hine, levy, editors. A Text book of oral pathology. $4^{\text {th }}$ ed. Pg-406.

2. Subrata S, Subrata S. Prevalence and severity of dental caries and oral hygiene status in rural and urban areas of Calcutta. J Indian Soc Pedo Prev Dent 1996; 14:17-20.

3. Freire MCM, Melo RB, Silva SA. Dental caries prevalence in relation to socioeconomic status of nursery school children in Goianiago, Brazil. Community Dent. Oral Epidemiol 1996;24:357-61.

4. Sebistitin M, Joseph T, Ravidaran V. Prevalence of dental caries periodontal disease and dental fluorosis in children of rural Kerala. J Indian Soc Pedo Prev Dent 1996;14:93-96.

5. Bali RK, Mathur VB, Talwar PP, Chanana HB. National oral health survey and fluoride mapping 2002-03 India.

6. Census of India 2001: Data from the 2001 Census, including cities, villages and towns (Provisional)". Census Commission of India. Archived from the original on16-06-2004. Retrieved 12-102010.

7. World Health Organization, Oral Health Surveys, Basic Methods, $4^{\text {th }}$ Ed.Geneva; WHO: 1997.

8. Dhar V, Bhatnagar M. Dental caries and treatment needs of children (6-10years) in rural Udaipur, Rajastha. Indian J Dent Res 2009;20:256-60.

9. Wong M CM, Lo ECM, Schwarz E, Zhang HG. Oral health status and oral health behaviors in Chinese children. J Dent Res 2001;80:1459-65.

10. Yee R, Mc Donald. Caries experience of 5-6-year-old and 12-13-year-old schoolchildren in central and western Nepal. Int Dent J 2002;52:453-60.

11. David J, Wang NJ, Åstrøm AN, Kuriakose S. Dental caries and associated factors in 12-year-old school children in Thiruvananthapuram, Kerala, India. Int $J$ Paedia Dent 2005; 15:420-28.

12. Chironga L, Manji F. Dental caries in 12year-old urban and rural children in Zimbabwe. Community Dent Oral Epidemiol 1989;17:31-33.

13. Satish C, Chawla NT. Incidence of dental caries in Lucknow school going children. Journal of Indian Dent Asso 1979;51: 109-10.

14. Sherfudhin $H$, Abdullah A, Shaik $H$, Johansson A. Some aspects of dental health in young adult Indian vegetarians a pilot study. Acta Odontol Scand 1996:54:44-48.

15. Das UM, Beena JP, Azher U. Oral health status of 6- and 12-year-old school going children in Bangalore city: an epidemiological study. J Indian Soc Pedod Prev Dent 2009;27(1):6-8.

16. Mahesh Kumar P, Joseph T, Varma RB, Jayanthi M. Oral health status of 5 years and 12 years school going children in Chennai city - An epidemiological study. $J$ Indian Soc Pedo Prev Dent 2005;17-22.

17. Gaikwad RS, Indurkar MS. Prevalence of dental caries in school going children of Aurangabad in the year 1992. Journal Indian Dent Asso 1993:64:10.

18. Gangwar SK, Idris MZ, Bhushan V, Nirupam S, Saimbi CS, Jain VC. Bio-Social Correlates of Dental Caries in Rural Area of Lucknow. Journal Indian Dent Asso 1990;61:4. 